\title{
Association of Proton Pump Inhibitor with Hypomagnesaemia: A Cross-Sectional Study at a Tertiary Care Hospital of Anand District
}

\author{
Dunkin U S*, and Punam D S \\ Department of Clinical Pharmacy A.R. College of Pharmacy, Vallabh Vidhyanagar, Gujarat, India
}

\begin{abstract}
Proton pump inhibitors (PPIs) are one of the most commonly used class of drugs for gastroesophageal reflux disease and number of other common persistent conditions. Hence, risk of potential long-term side effects associated with the use of PPIs is increasing. On March 2, 2011, the US FDA informed the public of the risk of hypomagnesaemia associated with prolonged usage of PPIs. Hence, the present study was undertaken to estimate the risk of development of hypomagnesaemia in patients who have been treatment with PPIs for at least one month and to check whether PPI induced hypomagnesaemia is a long term side effect with all PPIs. General demographic data, type of PPI used along with its duration of use and dose, morbid conditions, concomitant illness and several other confounders available from the basic metabolic panel of 60 patients (30 long term PPI users and 30 non PPI users), was collected and documented using a structured questionnaire. Serum magnesium levels of all 60 patients were estimated and data collected was analysed using T-test and ANOVA. Users on PPIs and non users had a mean serum magnesium level of $1.848 \pm 0.023 \mathrm{mg} / \mathrm{dL}$ and 2.167 $\pm 0.34 \mathrm{mg} / \mathrm{dL}$ respectively, with the difference being statistically significant $(p=0.00)$ and was independent of age, gender and concomitant drugs prescribed. However female PPI users had slightly lower serum Mg levels. Of the 30 recruited PPI users, 4 were asymptomatic hypomagnesaemic (serum $\mathrm{Mg}$ levels $<1.7 \mathrm{mg} / \mathrm{dL}$ ). Mean serum Mg levels in esomeprazole users were slightly higher than those on omeprazole or pantoprazole, with a statistically insignificant difference.
\end{abstract}

Keywords: Proton pumps inhibitors, Hypomagnesaemia, Omeprazole, Serum magnesium.

\section{INTRODUCTION}

Proton pump inhibitors (PPIs) are one of the most widely used class of drugs. They have been proven to have a very favourable safety profile, making it unusual for a patient to discontinue the drug due to side effects. However increasing number of patients are receiving long-term treatment with PPIs for gastroesophageal reflux disease (GERD) and a number of other common persistent conditions, hence increasing the vulnerability of possible long term side effects. ${ }^{1}$
Epidemiological studies have demonstrated that the use of PPIs is associated with an increased risk for pneumonia, enteric microbial growth and sepsis, although the attributed risk may be dependent upon the confounding factors. One area that is receiving much attention and generally that has been poorly studied is the long term effect of chronic acid suppression on the absorption of vitamins and nutrients. ${ }^{1}$ On March 2, 2011, the US FDA informed the public of the possible risk of hypomagnesaemia associated with prolonged usage of PPIs. ${ }^{2}$
Submitted Date : 18-05-2014 Accepted Date : 04-06-2014

DOI: 10.5530/ijopp.7.2.3

Address for correspondence:

Dr. Dunkin Shah

B Wing-204 Lake bloom residency, Near Larsen and Toubro gate\#6,, Powai, Mumbai, India-400072

Mobbile: +919833962914 E-mail: dunkinshah@gmail. com

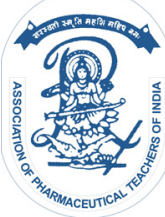

www.ijopp.org 
Although this risk is recognized as a rare side effect with PPIs, hypomagnesaemia is a serious condition that can be complicated by life threatening arrhythmias and neurologic manifestations. ${ }^{3,4}$

Most reports on PPI induced hypomagnesaemia concern omeprazole or esomeprazole (s-isomer of omeprazole). However, the recurrence of this side effect after substitution with other PPIs suggests that this is a class effect commonly seen following treatment with PPIs. ${ }^{5}$

A direct retrospective data analysis of hospitalized patients identified PPI use to be associated with lower serum $\mathrm{Mg}$ levels. ${ }^{6} \mathrm{~A}$ few other case reports showed the use of PPIs resulted in profound but reversible isolated hyponatremia, hypocalcaemia and hypokalemia. ${ }^{7-10}$ And importantly over the last five years, several clinical case reports have been published demonstrating that the use of PPIs is associated with the induction of severe hypomagnesaemia. ${ }^{11-14}$

Hypomagnesaemia leads to the onset of severe symptoms such as seizures, tetany, convulsions, cardiac arrhythmia and also putting the patients at risk for concomitant secondary electrolyte disturbances such as hypocalcaemia. ${ }^{15}$ Thus, the present study was undertaken to investigate the dynamics of serum $\mathrm{Mg}$ in patients who have been on treatment with PPIs for atleast one month and to investigate whether proton pump induced hypomagnesaemia (PPIH) is a genuine long term drug class effect with the use of PPIs.

\section{MATERIALS AND METHODS}

\section{Research design: Cross sectional study}

Inclusion criteria: Patients in the age group of 18-80 years who were on treatment with PPIs for a period of at least one month and those who were not on any PPI therapy despite having similar morbid conditions were included in the study.

Exclusion criteria: Patients with hepatic or renal impairment, pregnant or nursing women, patients suffering from acute pancreatitis, diarrhoea and congestive heart failure, and patients receving drugs which affect serum $\mathrm{Mg}$ levels such as ethacrynic acid, furosemide, gentamycin, amphotericin B, cyclosporine digitalis, cisplatin and anti-hypertensives such as beta blockers and ACE inhibitors were excluded from the study.
The present study was a cross-sectional study over a period of four months. Approval was obtained from the Human Research Ethics Committee of Shree Krishna Hospital in the Anand district. As per the protocol, 60 patients were recruited in the study of which 30 were receiving treatment with PPIs for at least one month (PPI users), while the other 30 were the cases of patients with similar morbid conditions but not on any PPI therapy (non PPI users). The scientific data of these 60 subjects were collected based on the inclusion-exclusion criteria. Informed consent of the recruited patients was taken before enrolling them into the study. Serum $\mathrm{Mg}$ levels of all the 60 patients were estimated at Pathological Laboratory of Shree Krishna Hospital using the colorimetric method. All the patient data was collected and recorded in the case record form (CRF) which included general demographic data, condition for which the PPIs were prescribed, the PPI prescribed along with its dose and duration of use, details of other concomitant drugs prescribed, serum $\mathrm{Mg}$ levels and other serum levels such as creatinine, albumin, sodium, potassium, chloride, total calcium if available, and symptoms associated with hypomagnesaemia. The scientific data was analysed using appropriate statistical tests such as frequency distribution, T-test and ANOVA.

\section{RESULTS}

Of all the 60 patients whose data was collected, 28 were male and 32 were female. Based on their age, subjects were categorized into three categories: $20-40$ years, $41-60$ years and $61-80$ years. The mean ages of the PPI users and non PPI users were $\mathbf{5 0 . 7 3} \pm 2.785$ years and $45.27 \pm 2.533$ years respectively.

\section{Serum Mg levels in PPI users and non PPI users:}

The normal serum $\mathrm{Mg}$ level in a healthy adult is 1.7-2.4 $\mathrm{mg} / \mathrm{dL}{ }^{16}$ Hypomagnesaemia is defined as serum Mg levels less than the normal range. Table 1 shows the mean serum Mg levels in PPI users and non PPI users. As it is evident from the table 1 that serum $\mathrm{Mg}$ levels in both the groups fall almost within the normal range, but comparing the mean serum Mg levels between the PPI users non users PPI users, it was observed that PPI users had significantly lower serum $\mathrm{Mg}$ levels $(\mathrm{p}<0.05)$. An important observation of this study was that out of the 30 PPI users whose data was collected, 4 of them had serum $\mathrm{Mg}$ levels lesser than $1.7 \mathrm{mg} / \mathrm{dL}$, depicting hypomagnesaemia which was asymptomatic.

Table 1: Mean serum Mg levels in PPI users and non PPI users

\begin{tabular}{cccc} 
Parameter & $\begin{array}{c}\text { PPI users } \\
(\mathbf{n}=\mathbf{3 0})\end{array}$ & Non PPI users $(\mathbf{n}=30)$ & $p$-value \\
\hline Serum Mg $(\mathrm{mg} / \mathrm{dL})$ & $1.848 \pm 0.02448$ & $2.167 \pm 0.03419$ & $0.000^{*}$ \\
\hline
\end{tabular}

Values are Mean \pm SEM, ${ }^{*} p<0.05$, statistically significant by t-test 


\section{Serum Mg levels with respect to the age group of patients}

Table 2 shows the comparison of the mean serum $\mathrm{Mg}$ levels in PPI users and non PPI users based on their age groups. As it is evident from the table that mean serum $\mathrm{Mg}$ level was found to be lower in PPI users of all age groups as compared to non PPI users, and the difference was found to be statistically significant $(\mathrm{p}<0.05)$.

\section{Table 2: Mean serum Mg levels in PPI users and non PPI users based on age of users}

\begin{tabular}{cccc}
$\begin{array}{c}\text { Age group } \\
\text { (year) }\end{array}$ & $\begin{array}{c}\text { Mean serum Mg level of } \\
\text { PPI users }(\mathbf{n = 3 0}) \\
(\mathbf{m g} / \mathbf{d L})\end{array}$ & $\begin{array}{c}\text { Mean serum } \mathbf{M g} \text { level of } \\
\text { non PPI-users }(\mathbf{n}=\mathbf{3 0}) \\
(\mathbf{m g} / \mathbf{d L})\end{array}$ & $p$-value \\
\hline $\mathbf{2 0 - 4 0}$ & $1.892 \pm 0.02798$ & $2.173 \pm 0.05742$ & $0.000^{*}$ \\
$\mathbf{4 1 - 6 0}$ & $1.862 \pm 0.04080$ & $2.174 \pm 0.04148$ & $0.000^{*}$ \\
$\mathbf{6 1 - 8 0}$ & $1.784 \pm 0.05124$ & $2.133 \pm 0.1936$ & $0.035^{\star}$ \\
\hline
\end{tabular}

Values are Mean \pm SEM, ${ }^{*} p<0.05$, statistically significant by one way ANOVA

\section{Mean serum Mg levels in PPI users and non PPI users based on gender}

Table 3 shows the mean serum Mg levels in PPI users and non PPI users based on their genders. The mean serum $\mathrm{Mg}$ level was significantly $(\mathrm{p}=0.000)$ lower in females as compared to males in both PPI users as well as non PPI users.

Table 3: Mean serum Mg levels in PPI users and non PPI users based on their gender

\begin{tabular}{cccc} 
Gender & $\begin{array}{c}\text { Mean serum Mg level in PPI } \\
\text { users }(\mathbf{n = 3 0})\end{array}$ & $\begin{array}{c}\text { Mean serum Mg level in non } \\
\text { PPI users }(\mathbf{n}=\mathbf{3 0})\end{array}$ & $p$-value \\
\hline Male & $1.873 \pm 0.04561 \mathrm{n}=12$ & $2.212 \pm 0.05536 \mathrm{n}=16$ & $0.000^{*}$ \\
Female & $1.831 \pm 0.02768 \mathrm{n}=18$ & $2.116 \pm 0.03419 \mathrm{n}=14$ & $0.000^{*}$ \\
\hline
\end{tabular}

Values are Mean \pm SEM, ${ }^{*} p<0.05$, statistically significant by t-test

\section{Mean serum Mg levels with respect to the duration of use of PPI}

Of the 30 patients receiving PPIs, the duration of PPI use in thse patients ranged from 32 days to 780 days. Table 4 shows the mean serum $\mathrm{Mg}$ levels of PPI users with respect to the duration of use and type of PPI prescribed. It is evident from the table that mean serum $\mathrm{Mg}$ level was slightly higher in those patients receiving esomeprazole as compared to those receiving omeprazole or pantoprazole. However the difference in mean serum $\mathrm{Mg}$ levels between the patients receiving pantoprazole, omeprazole and esomeprazole was not statistically significant by one way ANOVA.

Table 4: Mean serum Mg levels with respect to the duration of use of PPI

\begin{tabular}{cccc} 
Type of PPI & Duration of use (Mean) & Mean serum Mg level $(\mathbf{m g} / \mathbf{d L})$ of PPI users & $p$-value \\
\hline Pantoprazole & 141.9 days & $1.829 \pm 0.03220$ & 0.5269 \\
Omeprazole & 99.86 days & $1.860 \pm 0.05757$ & \\
Esomeprazole & 90 days & $1.913 \pm 0.01652$ & \\
\hline
\end{tabular}

Values in the table are Mean \pm SEM, $p>0.05$, statistically insignificant by one way ANOVA

\section{Mean serum Mg levels in PPI users and non PPI users based on concomitant drugs}

The use of PPIs was commonly seen in patients receiving anti-hypertensives, anti-diabetics, analgesics, antibiotics, anti-convulsants, anti-emetics, statins or psychiatric drugs, in order to suppress dyspepsia associated with the use of these drugs. PPIs were also prescribed to patients receiving corticosteroids, thyroxine sodium, acyclovir, cyclopam, baclofen, sucralfate, and tolperisone. Data of non PPI users was also obtained from patients using similar types of drugs. (Table 5) shows mean serum Mg levels in PPI users and non PPI users based on the use of other concomitant drugs. It is evident from this table that the serum $\mathrm{Mg}$ levelsamong all PPI users was low when compared to non PPI users, with a highly significant difference $(p<0.05)$ irrespective of the concomitant drugs prescribed. 
Table 5: Mean serum Mg levels in PPI users and non PPI users based on the concomitant drugs prescribed

\begin{tabular}{|c|c|c|c|}
\hline Drug Class & $\begin{array}{l}\text { Mean serum Mg level of } \\
\text { PPI users }(n=30) \\
\text { (mg/dL) }\end{array}$ & $\begin{array}{c}\text { Mean serum Mg level of } \\
\text { non PPI users }(n=30) \\
\text { (mg/dL) }\end{array}$ & $p$-value \\
\hline Anti-hypertensives & $1.817 \pm 0.04569 n=13$ & $2.237 \pm 0.08403 n=7$ & $0.000674362^{*}$ \\
\hline Anti-convulsants & $1.785 \pm 0.05130 n=6$ & $2.423 \pm 0.09939 n=3$ & $0.005334873^{*}$ \\
\hline Analgesics & $1.876 \pm 0.04018 n=8$ & $2.144 \pm 0.05976 n=14$ & $0.000688^{*}$ \\
\hline Anti-diabetics & $1.794 \pm 0.05352 n=9$ & $2.066 \pm 0.1179 n=5$ & $0.0403736^{*}$ \\
\hline Antibiotics & $1.842 \pm 0.02884 n=12$ & $2.226 \pm 0.06944 n=11$ & $0.000^{*}$ \\
\hline Anti-emetics & $1.808 \pm 0.05160 n=6$ & $2.168 \pm 0.1322 n=4$ & $0.032329817^{*}$ \\
\hline Calcium supplements & $1.853 \pm 0.05220 n=6$ & $1.997 \pm 0.05103 n=6$ & $0.0389915^{\star}$ \\
\hline Psychiatric drugs & $1.893 \pm 0.02068 n=8$ & $2.174 \pm 0.04407 n=9$ & $0.000^{*}$ \\
\hline Anti-asthmatics & $1.882 \pm 0.02437 n=5$ & $2.183 \pm 0.04626 n=4$ & $0.001117941^{*}$ \\
\hline Multivitamin preparations & $1.836 \pm 0.04448 n=10$ & $2.168 \pm 0.06680 n=6$ & $0.001259086^{*}$ \\
\hline Statins & $1.617 \pm 0.05783 n=3$ & $2.200 \pm 0.09460 n=5$ & $0.000949855^{\star}$ \\
\hline Anti-histaminics & $1.895 \pm 0.01500 n=2$ & $2.157 \pm 0.04449 n=19$ & $0.000^{*}$ \\
\hline Anti-platelets and anti-coagulants & $1.797 \pm 0.04724 n=7$ & $2.145 \pm 0.05500 n=2$ & $0.008615286^{*}$ \\
\hline Thyroid hormones & $1.810 \pm 0.05930 n=4$ & $2.355 \pm 0.1150 n=2$ & $0.02600332^{*}$ \\
\hline Others & $1.940 \pm 0.06940 n=4$ & $2.094 \pm 0.02952 n=8$ & 0.055558 \\
\hline
\end{tabular}

Values in the table are Mean \pm SEM, ${ }^{*} p<0.05$, statistically significant by t-tests

Mean serum levels of various variables among PPI users and non PPI users

To check the influence of the use of PPIs on various other variables like creatinine, sodium, potassium, chloride, calcium and albumin; the data of their serum levels was obtained from the case sheets of patients in whom they were routinely carried out. Data in table 6 shows the mean serum level of various variables among PPI users and non PPI users. Comparing the values of these variables with the normal range provided in the table, the values of all the variables are within the normal range.

\section{Table 6: Mean serum levels of various variables among PPI users and non PPI -users}

\begin{tabular}{ccccc} 
Variable & PPI users & Non PPI users & Normal range & $p$-value \\
\hline Serum Creatinine $(\mathrm{mg} / \mathrm{dL})$ & $0.6858 \pm 0.05586 \mathrm{n}=12$ & $0.6871 \pm 0.06046 \mathrm{n}=7$ & $\begin{array}{c}0.7-1.3(\text { Male) } \\
0.6-1.1(\text { Female) }\end{array}$ & 0.49375865 \\
Serum Sodium (mmol/L) & $135.2 \pm 1.589 \mathrm{n}=11$ & $138.0 \pm 1.592 \mathrm{n}=6$ & $135-145$ & 0.11610784 \\
Serum Potassium (mmol/L) & $3.591 \pm 0.3625 \mathrm{n}=11$ & $3.783 \pm 0.6187 \mathrm{n}=4$ & $3.5-5$ & 0.400003148 \\
Serum Chlorine (mEq/L) & $107.0 \pm 1.69 \mathrm{n}=6$ & $104.3 \pm 2.175 \mathrm{n}=4$ & $96-106$ & 0.178449534 \\
Serum Calcium (mg/dL) & $9.315 \pm 0.08253 \mathrm{n}=6$ & $9.043 \pm 0.2013 \mathrm{n}=4$ & $8.5-10.2$ & 0.13930954 \\
Serum Albumin $(\mathrm{gm} / \mathrm{dL})$ & $4.530 \pm 0.4437 \mathrm{n}=5$ & $4.495 \pm 0.3193 \mathrm{n}=6$ & $3.4-5.4$ & 0.475258938 \\
\hline
\end{tabular}

Values are Mean \pm SEM, $p>0.05$, statistically insignificant by t-test

\section{DISCUSSION}

Our cross-sectional study revealed that patients receiving PPIs had significantly lower serum $\mathrm{Mg}$ levels as compared to those patients not on any PPI therapy, which is in correlation with the results reported by JT
Gau et al. ${ }^{6}$ They also reported that PPI users had significantly lower serum $\mathrm{Mg}$ levels than non PPI users. An important observation of our study was that of the 30 patients who were receiving a PPI therapy, 4 of them had serum $\mathrm{Mg}$ levels lesser than $1.7 \mathrm{mg} / \mathrm{dL}$, i.e., they 
showed hypomagnesaemia which was however asymptomatic. Our results correlated with those of Hess et al who reported that many cases of PPIH are asymptomatic. ${ }^{16}$ Also, Takao Tamura et al reported that symptoms of PPIH did not occur until serum concentrations of Mg were less than $1.22 \mathrm{mg} / \mathrm{dL} .^{5}$

A very interesting observation in our study was that low serum Mg levels were seen in all age groups of patient's receving a PPI therapy, suggesting that age is not a factor influencing serum $\mathrm{Mg}$ levels. A similar observation has been reported by Hess et al. ${ }^{15}$ Another notable observation of our study was that serum Mg levels in female patients receiving PPIs were significantly lower as compared to the male counterparts. The reason for female preponderance in low serum $\mathrm{Mg}$ levels is unclear but it correlates with the results reported by Mackay JD et al. ${ }^{3}$

Evidence of hypomagnesaemia induced due to long term use of PPIs is available from various case reports wherein the use of PPIs ranged from 14 days up to 13 years (mean 5.5 years).$^{15}$ Duration of PPI use in our study population ranged between 32 days to 780 days, which is a very short period to confirm the evidence of association between the use of PPIs and hypomagnesaemia.

Tamura et al reported that PPIH was observed more frequently in patients receiving omeprazole or esomeprazole. ${ }^{5}$ Comparing the serum $\mathrm{Mg}$ levels in patients prescribed with different omeprazole, esomeprazole or pantoprazole, we observed that there was no significant difference in their respective mean serum $\mathrm{Mg}$ levels. However, the use of PPIs lowers serum Mg levels, irrespective of their types which suggests that PPIH may be a common drug class effect which correlates with the results reported by Hess et al and JT Gau et al. ${ }^{6,15}$ Other observations show that serum Mg levels in all PPI users were significantly low as compared to non PPI users which is irrespective of their morbid conditions and concomitant drugs prescribed.

A few case reports show that the use of PPIs result in profound but reversible isolated hyponatremia, hypocalcaemia and hypokalemia. ${ }^{7-10}$ In some cases, hypomagnesaemia is accompanied by hypokalemia and/ or hypocalcaemia., ${ }^{3,17,18}$ Mackay reported that hypocalcaemia was evident in association with severe hypomagnesaemia. ${ }^{3}$ Gau JT et al reported that patients with lower serum albumin levels are more likely to have depleted levels of magnesium. ${ }^{6}$ Based on these reports, in order to check the influence of the use of PPIs on various other variables such as creatinine, sodium, potassium, chloride and albumin; the data of their serum levels was also recorded down for those patients in whom they were routinely carried out.
However we could not observe disturbances in these serum variables, which could possibly be due to the small sample size.

Reports of other studies state that there was no typical patient profile that was unique for PPIH and the final attribution of the symptoms and electrolyte abnormalities to PPIH sometimes take years and in the absence of symptoms, identification of PPIH was purely dependent on chance. ${ }^{3,16,19}$

The mechanisms that explain lower serum $\mathrm{Mg}$ levels observed in patients receiving PPIs are not clear. Almost all of the cases reported in the literature have no evidence of renal $\mathrm{Mg}$ wasting except one case that suggested that a reduced efficiency of renal $\mathrm{Mg}$ conservation may be involved. ${ }^{12,20}$ Absorption of $\mathrm{Mg}$ from the GI tract is a complex process, in which both passive and active transport systems are involved. ${ }^{3,21}$ It is not known how PPI therapy may disturb each transport system in the GI tract despite some researchers suggesting that the PPI may affect the $\mathrm{Mg}$ active transport channels; transient receptor potential melastatin subtype 6 (TRPM6) which is responsible for the absorption of $\mathrm{Mg}$ in the kidney and GI tract. ${ }^{21-23}$

Thus, results of our study depict that long-term use of PPIs reduces serum Mg levels though not to the extent of causing significant hypomagnesaemia which support the general notion that PPI therapy may lead to subclinical degrees of low $\mathrm{Mg}$ levels or deplete $\mathrm{Mg}$ stores as suggested by the $\mathrm{FDA}^{2}$ and other supporting literatures. ${ }^{24}$

Limitations: (a) The sample size was too small because of fund limitation and shortage of time. (b) Dietary intake of $\mathrm{Mg}$ was not taken into account while taking the patient data. (c) Data of serum $\mathrm{Mg}$ levels before and after the initiation of PPI therapy was unavailable. (d) Because our study was cross-sectional, our findings can only imply an association but not a cause-and-effect relationship.

\section{CONCLUSION}

Our cross-sectional study revealed that significantly lower serum Mg levels were observed in patients receiving PPI therapy as compared to those patients not on any PPI, and it implies that long-term use of PPIs could be associated with sub-clinical Mg insufficiency or deficiency status. Thus we conclude that patients receiving PPIs are at increased risk of developing hypomagnesaemia, which could be asymptomatic in the initial stages but may turn symptomatic on the long run. Hence routine monitoring of serum $\mathrm{Mg}$ levels is essential for the patients who are on long term PPI therapy to prevent the risk of developing PPIH. 
Our results also suggested that since different types of PPIs were involved with low serum Mg levels or hypomagnesaemia, we can collectively conclude that it is a class effect of all PPIs. Future prospective studies that include pre-treatment and post-treatment $\mathrm{Mg}$ levels when initiating PPI therapy wouldbe able to provide more direct evidence of the association of PPIs and hypomagnesaemia and would also be able to clarify its underlying mechanism(s).

\section{ACKNOWLEDGEMENT}

We are very grateful to the Charutar Vidya Mandal to have provided us with the financial support to estimate serum Mg levels of all the patients recruited in the study. We are very thankful to Dr. Ajay Mishra, MD (General Medicine) from Shree Krishna Hospital, Karamsad for his valuable suggestions and guidance throughout the study.

\section{CONFLICTS OF INTEREST}

Authors declare no conflict of interest.

\section{ABBREVIATION}

PPI: Proton Pump Inhibitors

US FDA: United States Food and Drug Administration ANOVA: Analysis Of Variance

GERD: Gastroesophageal Reflux Disease

PPIH: Proton Pump Induced Hypomagnesaemia

ACE: Angiotensin Converting Enzyme Inhibitor

CRF: Case Record Form

\section{REFERENCES}

1. Ito $\mathrm{T}$, Jensen RT. Association of long term proton pump inhibitor therapy with bone fractures and effects on absorption of calcium, vitamin, $\mathrm{B}_{12}$, iron and magnesium. Curr Gastroenterol Rep. 2010; 12: 448-57.

2. U.S. Food and Drug Administration. Low Magnesium levels can be associated with long term use of proton pump inhibitors (PPIs). Drug Safety Communication. March; 2011. Available from: http://www.fda.gov/Drugs/ DrugSafety/ucm245011.htm
3. Mackay JD, Bladon PT. Hypomagnesaemia due to proton-pump inhibitor therapy: A clinical case series. QJM. 2010; 103: 387-95.

4. Cundy T, Mackay J. Proton pump inhibitors and severe hypomagnesaemia. Curr Opin Gastroenterol. 2011; 27 (1): 180-85.

5. Tamura T, Sakaeda $\mathrm{T}$ et al. Omeprazole and Esomeprazole-associated Hypomagnesaemia: Data Mining of the Public Version of the FDA Adverse Event Reporting System. International Journal of Medical Sciences. 2012; 9: 322-36.

6. Gau JT, Yang YX, Chen R, et al. Uses of proton pump inhibitors and hypomagnesaemia. Pharmacoepidemiol Drug Saf. 2012; 21: 553-59.

7. Melville C, Shah A, Matthew D, et al. Electrolyte disturbance with omeprazole therapy. Eur J Pediatr. 1994; 153: 49-51.

8. Nealis TB, Howden CW. Is there a dark side to long-term proton pump inhibitor therapy? Am J Ther. 2008; 15: 536-42.

9. Lodato F, Azzaroli F, Turco L, et al. Adverse effects of proton pump inhibitors. Best Pract Res Clin Gastroenterol. 2010; 24: 193-201.

10. Insogna $\mathrm{KL}$. The effect of proton pump-inhibiting drugs on mineral metabolism. Am J Gastroenterol. 2009; 104: S2-4.

11. Broeren MA, Geerdink EA, Vader HL, et al. Hypomagnesemia induced by several proton-pump inhibitors. Ann Intern Med. 2009; 151: 755-56.

12. Kuipers MT, Thang HD, Arntzenius AB. Hypomagnesaemia due to use of proton pump inhibitors-A review. Neth J Med. 2009; 67: 169-72.

13. Quasdorff M, Mertens J, Dinter J, et al. Recurrent hypomagnesemia with proton-pump inhibitor rechallenge. Ann Intern Med. 2011; 155: 405-07.

14. Fernandez-Fernandez FJ, Sesma P, Cainzos-Romero T, et al. Intermittent use of pantoprazole and famotidine in severe hypomagnesaemia due to omeprazole. Neth J Med. 2010; 68: 329-30.

15. Hess MW, Hoenderop JG. Systemic review: Hypomagnesaemia induced by proton pump inhibition. Aliment PharmacolTher. 2012; 36: 405-13

16. Burtis CA, Ashwood ER, Bruns DE. Fundamentals of Clinical Chemistry.

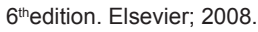

17. Kuiper MT, Thang HD.Hypomagnesaemia due to use of proton pump inhibitors: A review. Netherlands The Journal of Medicine. 2009; 67: 169-72.

18. Hoorn EJ, van der Hoek J, de Man RA, et al. A case series of proton pump inhibitor-induced hypomagnesaemia. A J Kidney Dis. 2010; 112-16.

19. Macias AG, Lahuerta JI, De Castro MA, et al. Severe hypomagnesaemia related to omeprazole. Rev Clin Esp. 2011; 211: 488-9.

20. Regolisti G, Cabassi A, Parenti E, et al. Severe hypomagnesaemia during long term treatment with proton pump inhibitor. Am J Kidney Dis. 2010; 56: 168-74.

21. Quamme GA. Recent developments in intestinal magnesium absorption. Curr Opin Gastroenterol. 2008; 24: 230-35.

22. Schlingmann KP, Weber S, Peters M. et al. Hypomagnesaemia with secondary hypocalcaemia is caused by mutations in TRPM6, a new member of the TRPM gene family. Nat Genet. 2002; 31: 166-70.

23. Schlingmann KP, Waldegger S, Konrad M, et al. TRPM6 and TRPM7: Gatekeepers of human magnesium metabolism. Biochem Biophys Acta. 2007; 1772: 823-21.

24. Yang YX, Metz DC. Safety of proton pump inhibitor exposure. Gastroenterology. 2010; 139: 1115-27. 